\title{
AS INFINITAS MÁSCARAS DA CIDADE ${ }^{1}$ \\ — O Patrimônio Histórico Cultural como Espaço Espetacular —
}

Leon de Paula ${ }^{2}$

Palavras- Chave: Espaço Teatral; Concepção do Espetáculo; Explosão do Espaço Teatral; Teatro Catarinense

Resumo: Com este estudo, tenho por objetivo o resgate das iniciativas realizadas nas décadas de 1980 e 1990 por grupos de teatro de Florianópolis que se serviram do sentido simbólico e monumental de espaços de tipologia não-italiana, componentes do patrimônio histórico e cultural dessa cidade, para a composição da obra de arte teatral.

Nas décadas de 1980 e 1990 houve em Florianópolis uma recorrência, por parte de alguns grupos teatrais locais, em realizar espetáculos em espaços patrimoniais de tipologia não-italiana. Vários foram os espetáculos apresentados por diferentes grupos que se apropriaram de lugares abertos ou fechados para sua prática cênica espetacular, lugares esses conhecidos como espaços que constituem patrimônio histórico e cultural da cidade, possuidores de arquitetura de tipologia não-italiana.

Numa primeira pesquisa feita nos jornais O Estado, Jornal de Santa Catarina, A Notícia, A Gazeta e Diário Catarinense (de abragência estadual), da década de 1980, foi possível identificar como expoente dessa prática o trabalho desenvolvido pelo diretor Wilson Rio Apa, onde, entre outros trabalhos, A Paixão de Cristo Segundo Todos os Homens, realizado nas dunas da Lagoa da Conceição, é a obra que mais destaca a sua iniciativa. Nessa mesma década, segundo estes jornais, o grupo "Dromedário Loquaz" iniciou esse tipo de apropriação em Florianópolis encenando no antigo prédio da Alfândega da cidade A Importância de Estar de Acordo, Curto Circuito e As Hienas, dirigidos por Isnard Azevedo. Ainda nesse período, tivemos os trabalhos realizados pelo grupo "A de Teatro", que encenou A Indecisa e Ícaro, na hoje inexistente sede da Sociedade de Tiro Alvo Alemão.

A década de 1990 apontou, na pesquisa inicial, para uma intensificação de utilização de espaços histórico-culturais de Florianópolis de tipologia não-italiana, como espaço possível para realização dos espetáculos por parte dos grupos locais.

\footnotetext{
${ }^{1}$ Artigo produzido sob orientação da Prof ${ }^{a}$ Dra. Vera Regina Martins Collaço, no $1^{\circ}$ semestre de 2007, no Programa de Pós-Graduação em Teatro - PPGT - Udesc/Ceart.

${ }^{2}$ Aluno do PPGT/ Ceart-Udesc, $1^{\circ}$ semestre de 2007. Ator integrante do grupo "Teatro, Sim... Por Quê Não?!!” e professor de teatro, formado pelo Curso de Licenciatura Plena em Educação Artística Habilitação Artes Cênicas da Udesc/Ceart. 
Destaca-se, nesse período, o trabalho de Sulanger Bavaresco com Agnus Dei, no prédio da Faculdade de Educação-UDESC; o trabalho de Fátima Lima, com Dois, no Forte Sant'Anna; O Auto da Estrela Guia, na Praça XV de Novembro, com direção de Mário Santana; e Nivaldo Matos, com Os Lobos, nos fundos da Casa de Teatro Armação. Além desses, houve também a ópera $O$ Guarani, promovida pela Prefeitura Municipal de Florianópolis, sob regência do maestro Júlio Medaglia, no Largo da Catedral Metropolitana de Florianópolis.

A par desta configuração local, percebe-se que a partir da década de 1970, com novas diretrizes da UNESCO em relação à questão patrimonial, espraia-se, no mundo ocidental, um "pensamento combativo e inovador [...] que motivaram a organização de eventos internacionais para os impasses da preservação do patrimônio diante da expansão urbana e industrial". (FUNARI E PELEGRINI, 2006:31) ${ }^{3}$

Mas, como dizem Funari e Pelegrini, "devemos ter sempre em mente que as políticas de preservação do patrimônio cultural nos países da América Latina ainda são muito recentes. Em termos práticos, elas surgiram a partir do momento em que a UNESCO reconheceu alguns bens-culturais latino-americanos como patrimônio da humanidade [1972]". (2006, 29-30).

A partir da década de 1970 ampliou-se também a noção de patrimônio histórico, que passou para patrimônio cultural, implicando numa visão mais abrangente:

A definição de patrimônio passou a ser pautada pelos referenciais culturais dos povos, pela percepção dos bens culturais nas dimensões testemunhais do cotidiano e das realizações tangíveis. (FUNARI e PELEGRINI, 2006:32).

Esta nova percepção ou relação com a cidade e com os espaços para a realização de espetáculos também se difundiu no mundo teatral. Na Europa, de acordo com JAVIER $^{4}$ (1998:40) nas décadas de 1970 e 1980 ocorreu a preferência de alguns diretores e produtores teatrais por realizar espetáculos em locais, que ele denomina "parateatrales", numa recusa dos edifícios — em sua grande parte, de tipologia italiana - construídos especificamente para esse fim.

Diante de tal compreensão, algumas questões começaram a se formular com relação ao teatro produzido em Florianópolis nas décadas de 1980 e 1990, a respeito da concepção desses espetáculos para espaços não-italianos, referenciados como monumentos históricos e culturais da cidade:

3 FUNARI, Pedro Paulo e PELEGRINI, Sandra C. A. Patrimônio Histórico e Cultural. Rio de Janeiro: Jorge Zahar, 2006.

4 JAVIER, Francisco. El Espacio Escénico como Sistema Significante. Buenos Aires: Leviatán, 1998. 
A valorização do patrimônio cultural e a necessidade de reabilitar os centros históricos, na atualidade, constituem premissas básicas dos debates sobre o desenvolvimento sustentável nas cidades latino- americanas, pois esses centros representam a síntese da diversidade que caracteriza a própria cidade. (FUNARI e PELEGRINI, 2006:29)

Afirma ROUBINE (1982:73) ${ }^{5}$ que o século XX “parece ter sido o que primeiro tomou consciência do caráter histórico da chamada representação à italiana”. Os questionamentos com relação a este espaço teatral tiveram início, segundo Roubine, com a proposição cênica de André Antoine, em 1890: ou seja, no apagar das luzes do século XIX. Questionamentos iniciais que estiveram interligados com o debate e as tentativas de democratização do teatro.

As tentativas de reformular o espaço à italiana tanto no final do século XIX quanto na primeira metade do século $\mathrm{XX}$, não romperam com a barreira da mais demorada queda: a que estabelecia a relação fixa entre espectadores e atores. Artaud "foi sem dúvida um dos que primeiro compreenderam, nos anos 1920, que a invenção de um novo teatro implicava a transformação das relações entre platéia e espetáculo, ou seja, em última análise, a explosão do palco”. (ROUBINE, 1982:78).

No início do século XX o palco italiano torna-se objeto de amadurecida reflexão e argumentação:

Quer dizer que ele não é mais considerado como uma estrutura natural, inerente à própria essência da arte teatral, e portanto inexcedível e incontornável, mas como conseqüência histórica de uma evolução em marcha, um sistema aberto suscetível de ser transformado e aperfeiçoado. (ROUBINE, 1982:79).

A segunda metade do século $\mathrm{XX}$ assistiu e experimentou o rompimento preconizado por Artaud, na primeira metade desse século, com relação ao espaço à italiana:

\begin{abstract}
Nossa época assistiu a um grande florescimento de experiências inspiradas nas teses artaudianas, ou em exata convergência com elas. As tentativas do Living Theatre nos Estados Unidos e, a seguir na Europa, as buscas de Peter Brook na Inglaterra e de Jerzy Grotowski na Polônia constituem sem dúvida dos empreendimentos mais rigorosos e bem-sucedidos sob este aspecto. (ROUBINE, 1982:89)
\end{abstract}

Na década de 1960 do século XX são as experiências cênicas de Jerzy Grotowski, Ariane Mnouchkine e Luca Ronconi - na Europa - e do grupo Living Theater - nos Estados Unidos - que, no ocidente, rompem definitivamente com o espaço teatral de tipologia italiana. Esses novos espaços ocupados para abrigarem os

ROUBINE, Jean-Jacques. A Linguagem da Encenação Teatral. Rio de Janeiro: Zahar, 1982. 
seus espetáculos (galpões, ruas, praças etc.) estabeleceram novas e amplas relações entre os atores e o seu público. O espaço não só aparece "explodido", como também “fragmentado". O espectador destes espetáculos não está mais fixado num determinado e exclusivo ponto, o mesmo pode se dar com as cenas, estas podem ser simultâneas, o que fragmenta ainda mais a visão e o acompanhamento do espetáculo. $\mathrm{O}$ espaço agora pode não proporcionar "mais nenhuma zona especializada. Ao entrar, o espectador não encontra o seu lugar marcado". (ROUBINE, 1982:95):

Com Grotowski, Ronconi, Mnouchkine e muitos outros [...], o teatro liberta- se das suas amarras. O espaço teatral torna-se, ou volta a ser, uma estrutura completamente flexível e transformável de uma montagem para outra, quer se trate das áreas de representação ou das zonas reservadas ao público. (ROUBINE, 1982: 103)

Segundo Javier, a nova relação estabelecida entre ator e espectador, outro processo de comunicação, mais direto, resultou de uma busca de "una comunicación eficente, que alcance al espectador de lleno, y el papel que juega en ello el espacio escénico, explica en gran parte la seducción que los espacios no convencionales [...] exercem sobre os creadores del espectáculo y aun sobre el público”. (JAVIER, 1998:2526).

Faz-se necesario apresentar, a priori, algumas definiçõos que devem ser aprofundadas no decorrer do trabalho. Para apontar aqui algumas delas, que são centrais para este trabalho, utilizo como parâmetro o dicionário teatral de Pavis ${ }^{6}$ :

Espaço Cênico - Termo de uso contemporâneo para palco ou área de atuação. Considerando-se a explosão das formas cenográficas e a experimentação sobre novas relações palco-platéia vem a ser um termo cômodo, porque neutro, para descrever dispositivos polimorfos da área de atuação. (PAVIS, 1999:133).

Com relação ao termo que tenho empregado com razoável frequiência neste projeto - Espaço Teatral — Pavis apresenta a seguinte definição:

Termo que substitui frequentemente, hoje, teatro. Com a transformação das arquiteturas teatrais - em particular o recuo do palco italiano ou frontal - e o surgimento de novos espaços - escolas, fábricas, praças, mercados etc

— , o teatro se instala onde bem lhe parece, procurando antes de mais nada um contato mais estreito com um grupo social, e tentando escapar aos circuitos tradicionais da atividade teatral. O espaço cerca-se por vezes de um mistério e de uma poesia que impregnam totalmente o espetáculo que aí se dá. (PAVIS, 1999:138).

Ao trabalhar a questão das estruturas arquitetônicas não-italianas que acolhem o espetáculo teatral contemporâneo, Javier (1998:67) levanta alguns desses espaços

\footnotetext{
${ }^{6}$ PAVIS, Patrice. Dicionário de Teatro. São Paulo: Perspectiva, 1999.
} 
recorrentes na encenação atual, tais como: casas particulares, galpões, depósitos, sótãos, garagens, igrejas, castelos e palácios, ruínas, jardins públicos, praças, ruas, campos, bosques, etc. Esta é uma das partes da pesquisa aqui proposta, qual seja, a de levantar os lugares que foram utilizados para a realização do espetáculo, vinculados um ao outro de maneira muito específica: espaços que, sendo detentores de sentido histórico e cultural referenciais da memória da cidade, emprestaram aos grupos teatrais esse sentido simbólico como suporte para a concepção dos seus espetáculos.

Ao detalhar os diferentes locais onde podem ser realizados os espetáculos contemporâneos, Javier (1998:67) observa que

Las características del espacio escénico pueden ser tan variadas como los ámbitos puestos en funcionamiento. Generalmente, esas características dependen de la dramaturgia y de las relaciones que van apareciendo a medida que se ensaya y de las relaciones que se busca establecer entre actores y espectadores.

Antes de adentrar-me no Brasil e em específico em Santa Catarina sobre a questão do teatro contemporâneo, desejo apontar alguns referenciais teóricos, sobre uma das bases deste trabalho no que diz respeito ao patrimônio histórico e cultural.

A cidade-palco dos novos espaços teatrais e os centros urbanos como locais das realizações cênicas mais contemporâneas, no Brasil e especialmente em Florianópolis, são espaços também constantemente mutáveis, como diz Baudelaire (apud LE GOFF, 1998: 143)7: “A forma de uma cidade muda mais depressa, lamentavelmente, que o coração de um mortal. Ainda assim, a continuidade se firma em certas formas". E com isso tentamos "fixar uma representação da cidade que possamos dominar mentalmente, mobilizamos os recursos da história. A cidade contemporânea escapa às definições tradicionais, mas queremos atá-la ao pedestal de um patrimônio". (LE GOFF, 1998:143).

As cidades atuais também são fragmentadas, dispersas, justapõem uma multiplicidade de centros fragmentários. "E, consequentemente, os centros nevrálgicos se multiplicam. A cidade atual caminha em direção ao policentrismo". (LE GOFF, 1998:144). E, de maneira geral, nos centros das cidades é que estão situados os monumentos históricos e culturais. E, como observa Le Goff,

\footnotetext{
Há muito tempo os centros são objeto de ferozes batalhas; eles não querem desaparecer sem combate, eles resistem. Parece-me, entretanto, que a evolução age profundamente contra o centro urbano. Ele não é mais adaptado à vida econômica, à vida das relações que dominam as populações urbanas. Então, o que ele se torna? Centro storico, dizem muito bem os italianos. E se ele ainda brilha, é a beleza da morte. Caminha-se em direção ao centro-museu. (1998:150).
}

${ }^{7}$ LE GOFF, Jacques. Por Amor às Cidades. São Paulo: UNESP, 1998.

DAPesquisa, Florianópolis, v.2, n.4, p. 128-134, 2007. 
Este paradigma está posto também nas grandes e médias cidades brasileiras, especialmente nas capitais e em cidades turísticas, como é o caso de Florianópolis. A cidade expande-se para além do centro. Mas ainda é no centro que temos os referenciais artísticos mais fortes, e normalmente é nele que ainda se localizam muitas casas de espetáculo. E nisso reside o encanto desses espaços e talvez seu fascínio por parte dos novos agentes teatrais. Como afirma Le Goff: "Se o centro perde em energia, ganha em prestígio; é que ele permite ver num relance a cidade: sua beleza o resume". (1998:153). Retomando o eixo teatral, pode-se observar que, estando o Brasil na década de 1970 sob a ditadura militar, poucas foram — em relação à década de 1980 e 1990 — as experiências teatrais realizadas em espaços distintos do espaço à italiana, pois uma relação mais estreita entre ator e espectador sofria uma interferência direta da censura. Mesmo assim, o grupo "Oficina" realizou um trabalho como Gracias Señor e, por conta disso o diretor do grupo - José Celso Martinez Correa - se viu obrigado a deixar o país. Portanto, apenas com a restauração da democracia, que se deu a partir dos anos de 1980, é que foi possível expandir e "explodir" as novidades teatrais em "Terra Brasilis". Como se pode observar pela seguinte fala, "é verdade que as regras e modelos não se introduzem em tempo real e que é necessária uma intensa circulação de idéias e um ambiente propício para recebê-las”. (LIMA, 2006:35) ${ }^{8}$. Muitos foram os espetáculos que, encenados em espaços não-italianos por todo o Brasil às vésperas da década de 1980 (e também durante a década) questionaram, a sua maneira, o caráter "natural" do espaço à italiana de atender as necessidades dos artistas de teatro naquele contexto.

No Brasil, além do grupo "Oficina” em São Paulo, outros grupos também apresentavam esses anseios ao fim dos anos de 1970, como os grupos "Tribo de Atuadores Oi Nóis Aqui Traveiz”, de Porto Alegre e o "Tá na Rua”, do Rio de Janeiro, dentre outros; entre as décadas de 1960 e 1970, em âmbito internacional, grupos como "The Living Theater" e "Bread and Puppet" nos Estados Unidos, e encenadores europeus como Peter Brook, Jerzy Grotowski, Luca Ronconi e Ariane Mnouchkine estabelecem suas práticas artísticas para além das limitações dos espaços de tipologia italiana, numa busca teatral preconizada no início do séc.XX por diversos outros encenadores como Antoine e Meyerhold, e poetas do teatro (em especial, Antonin Artaud).

8 LIMA, Evelyn Furquim Werneck. Das Vanguardas à tradição: arquitetura, teatro \& espaço urbano. Rio de Janeiro: 7Letras, 2006. 
Na cena contemporânea brasileira, o apuro do trabalho do grupo paulista "Teatro da Vertigem" se destaca pelas investigações das relações do ator e do espectador em espaços não-italianos que - dentre os espaços utilizados para receber os espetáculos Paraíso Perdido, O Livro de Jô, Apocalipse 1,11 e BR-3 - tiveram até mesmo o seu sentido de referência de memória urbana esvaziado pelo crescimento da própria cidade.

Em Florianópolis, como observamos na exposição do problema a ser trabalhado nesta pesquisa, a questão de ruptura com o espaço de tipologia italiana se fez a partir da década de 1980. Contudo, ainda necessitamos aprofundar a pesquisa iniciada para analisar esse "movimento" realizado nas décadas de 1980 e 1990. Além disso, a pesquisa pretende analisar a razão das escolhas dos grupos de Florianópolis para elaborar seus espetáculos em espaços históricos e culturais da cidade, no mesmo período em que se espraiava no país uma intensa discussão de apropriação e revitalização dos centros históricos e da preservação dos monumentos materiais e imateriais.

\section{BIBLIOGRAFIA:}

ADAMS, Betina. Preservação Urbana: gestão e resgate de uma história: patrimônio de Florianópolis. Florianópolis: Ed. da UFSC, 2002.

FUNARI, Pedro Paulo e PELEGRINI, Sandra C. A. Patrimônio Histórico e Cultural. Rio de Janeiro: Jorge Zahar Editor, 2006.

JAVIER, Francisco. EI Espacio Escénico como Sistema Significante. Buenos Aires: Leviatán, 1998.

LE GOFF, Jacques. Por Amor às Cidades. São Paulo: UNESP, 1998.

LIMA, Fátima Costa. Espaços de Encontro no Teatro e no Carnaval. Florianópolis: Dissertação de Mestrado FAED/UDESC, 2003 (inédita).

LIMA, Evelyn Furquim Werneck. Das Vanguardas à tradição: arquitetura, teatro \& espaço urbano. Rio de Janeiro: 7Letras, 2006.

PAVIS, Patrice. Dicionário de Teatro. Tradução para a língua portuguesa sob a direção de Jacó Guinsburg e Maria Lúcia Pereira. São Paulo: Perspectiva,1999.

ROUBINE, Jean-Jacques. A Linguagem da Encenação Teatral. Tradução e apresentação de Yan Michalski. Rio de Janeiro: Zahar, 1982. 